\title{
Benchmarking Foundation Administrative Expenses: Update on How Operating Characteristics Affect Spending
}

\section{By Loren Renz, Research Consultant}

Questions about how much foundations spend on staff, overhead, and other administrative expenses - and how much is appropriate to spend-are a perennial focus of policy debates on foundation practices. Foundations themselves seek guidance on these questions. Yet often missing in these discussions is the need to consider how differences in foundations' infrastructure, operations, and programmatic activities affect their cost levels relative to their grantmaking. These differences are striking even among the largest independent foundations. Also overlooked is the issue of how extreme changes in the economy and stock market may affect the relationship of a foundation's administrative expenses to its total charitable distributions.

\section{Benchmarking Foundation Administrative Expenses explores how variations in} foundations' characteristics, activities, and giving levels influence charitable (programrelated) administrative expense levels for a sample of nearly 1,200 of the approximately 1,900 largest independent foundations between 2007 and 2009 (see "Sampling Information"). It updates a more detailed study of the largest foundations' 2004-2006 expenses. ${ }^{1}$ Since these organizations account for the bulk of foundation resources and spending, they are of paramount interest to policymakers, watchdog organizations, and foundation leaders concerned with self-regulation and developing standards. Like the previous report, this update builds on the foundations of a broader study of 2001-2003 expenses. ${ }^{2}$
This study's goals are to inform policy debates and foundation practices by documenting program-related administrative expenses and assessing the factors that drive these expenditures over time. By extending the research timeframe closer to the present, this study sheds light on expense levels and practices during the recent economic crisis. It confirms that expense patterns of large independent foundations that were clear and consistent in mid-decade-when markets and asset levels were steadily rising — remained mainly consistent in 2007-2009, despite the crash of financial markets and a deep slump in the economy and in foundation resources (see Foundation Finances and the Economic Crisis: A Different Perspective on page 6). Such consistency validates the importance of considering a foundation's operating characteristics when assessing its expenditures.

\section{FIGURE 1: Staffed Versus Unstaffed Large Independent Foundations by Giving Range,} 2007-2009

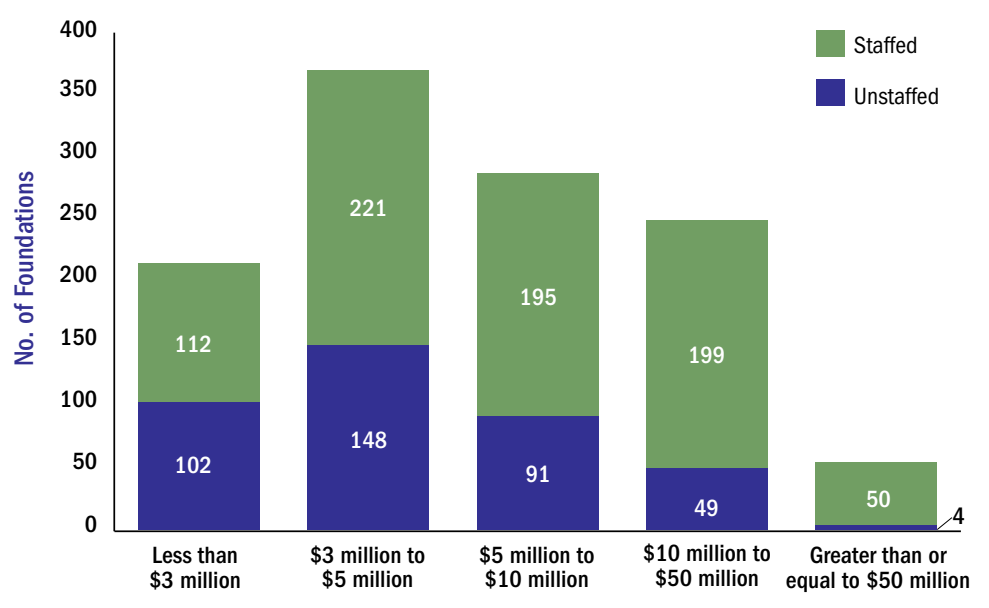

Source: The Foundation Center, 2012: The Foundation Finances Database (2007-2009). Sample includes 1,171 foundations that ranked among the approximately 1,900 largest foundations by giving in 2007,2008 , and 2009 for which data were available for all years; qualifying foundations gave at least \$2 million each year. Giving level is based on a three-year average for 2007 through 2009. 


\section{KEY FINDINGS}

\section{Operating Characteristics and Expense Patterns, 2007 to 2009}

\section{Independent foundations'}

characteristics strongly influence their charitable administrative expenses.

Even among the largest foundations, differences in giving levels, assets, operational styles, geographic reach, and programs vary dramatically and produce very different expense patterns. While some foundations in this study reported expenses in the millions in 2007-2009, one out of eight of these large grantmakers reported no expenses as part of their qualifying distributions in that period. One out of three had no paid staff (Figure 1). These foundations were likely functioning with volunteer labor and/or operating costs were absorbed by the donor or the donor's family business.

\section{Employment of staff is the single most important factor affecting expense levels, followed by staff size. \\ Paying staff significantly raises administrative costs, and expense levels rise consistently with the number of staff}

(Figure 2). Staff size, which varies greatly even among foundations with similar giving levels, depends on a foundation's mission, roles, and scope of activities. In general, the foundations that tend to give the most have the largest staffs. But smaller foundations with complex programs often have aboveaverage staff size relative to their giving.

\section{Foundations that employed staff} had median expense ratios of nearly 8 percent, on average, compared with less than 1 percent for those without staff.

Just 35 percent of staffed foundations had a ratio below 5 percent, while 93 percent of unstaffed foundations were in this range (Figure 3). At the other end of the spectrum, close to 3 percent of large independent staffed foundations (21) had ratios greater than 30 percent. $^{3}$

\section{International grantmaking, direct charitable activities, and grants-to- individuals programs are strongly associated with higher expense ratios. Foundations that engaged regularly in these practices between 2007 and 2009 had median expense-to-qualifying distribution ratios that were almost or at least twice as high as those that did not. These activities may have higher fixed}

costs, require more employees, or incur greater regulatory burdens. Besides these staff- and resource-intensive activities, other practices that substantially boosted a foundation's administrative expense levels were operating as a health-conversion foundation (see below), making programrelated investments, and/or maintaining a web site (a proxy for a broader communications effort).

\section{Foundations with high charitable} administrative expense ratios often mix grantmaking and direct charitable activities (DCAs).

While making grants is the primary function of most foundations, one out of five of the large staffed independent foundations studied regularly engaged in DCAs (Figure 4). These ranged from conducting health policy research to providing technical assistance to nonprofits to operating conference centers or museums. In fact, although they make grants, some independent foundations seem to function much like operating foundations and have among the highest expense ratios. ${ }^{4}$ As foundations increasingly take on nongrantmaking charitable activities, ${ }^{5}$ it is critical that studies of finances account for these program costs.
FIGURE 2: Charitable Administrative Expenses as a Share of Qualifying Distributions, 2007, 2008, and 2009: Staff Size (Staffed Independent Foundations)

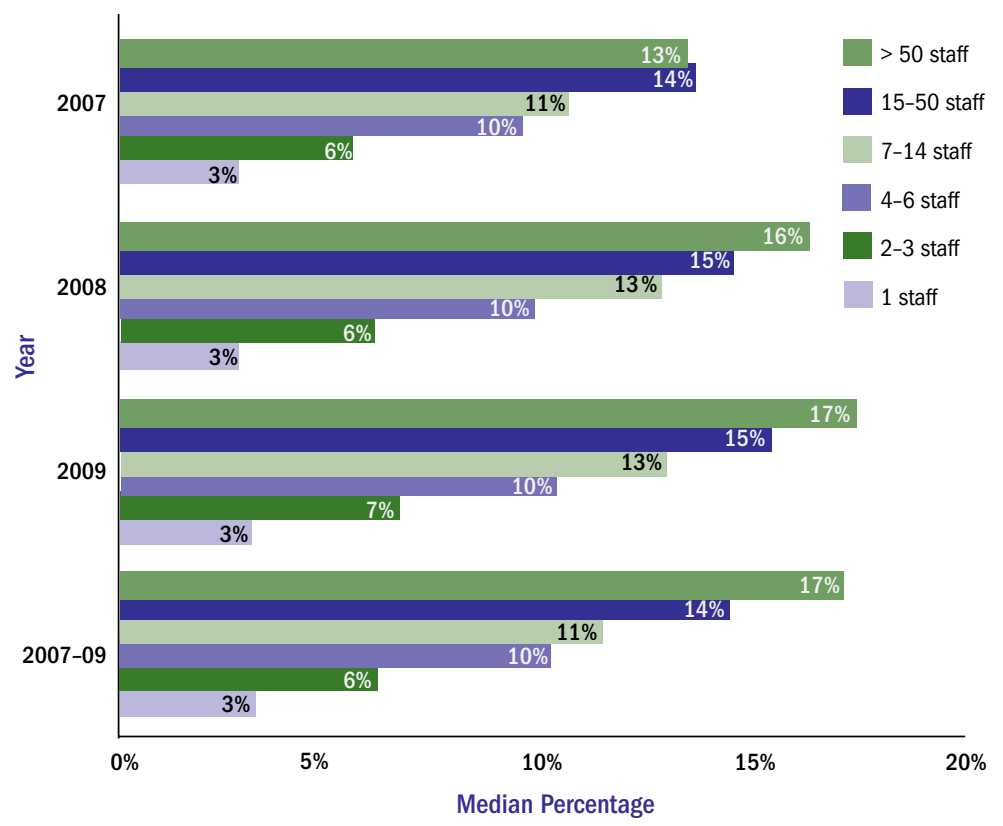

Source: The Foundation Center, 2012: The Foundation Finances Database (2007-2009). Sample includes 1,171 foundations that ranked among the approximately 1,900 largest foundations by giving in 2007,2008 , and 2009 for which data were available for all years; qualifying foundations gave at least $\$ 2$ million each year. Of the 1,171 foundations sampled, on average 777 reported having paid staff.

\section{Sampling Information}

This study focuses only on large independent foundations. The sample includes 1,171 foundations that ranked consistently among the approximately 1,900 largest independent and family foundations by giving in 2007, 2008, and 2009 and for which IRS Form 990-PF was available publicly for all years. These foundations each gave at least \$2 million in each study year. While foundations in the study represented just 2 percent of all independent foundations in 2007 , they accounted for 67 percent of all independent foundation giving in that year and 70 percent of all independent foundation assets. Aggregate financial data for these 1,171 foundations, including assets, giving, qualifying distributions, charitable expenses, and program-related compensation, are available at foundationcenter.org/ gainknowledge/research/ benchmarking/ 
Operating as a "health conversion" or "new health" foundation raises administrative expense levels, especially for smaller foundations.

This update confirms results first cited in the 2004-2006 foundation expenses study: being formed from the sale of a hospital or health organization has a strong effect on foundation spending. While this factor applied to just 30 of the staffed independent foundations in the 2007-2009 study, it more than doubled their median cost level (Figure 5). In fact, health conversion foundations were among those reporting the highest expense ratios. ${ }^{6}$ Higher than average staffing levels and the prevalence of direct charitable activities ${ }^{7}$ are among the factors that contribute to the higher expense levels associated with health conversion status.

\section{Foundation size influences cost ratios.}

Foundations with more resources tend to employ a higher number of staff, have more complex infrastructure, and engage in more complex activities. At the same time, the largest foundations also enjoy some economies of scale, so they can achieve lower cost ratios for certain activities, such as international grantmaking, direct charitable activities, program-related investments, and operating as a healthconversion foundation.

\section{Donor-family involvement and operating as a non-endowed-or "pass-through"-foundation usually lowers charitable administrative expense ratios in staffed foundations.}

Family foundations, which represent the majority of staffed foundations, had a median expense ratio of 6 percent, compared to 10 percent for foundations with little or no family involvement (Figure 6). The relatively few staffed pass-through foundations had a 3 percent median expense ratio, compared with 8 percent for endowed foundations. Most likely, family members help hold down staff-related costs by providing program administration and other assistance. Pass-through foundations, which have no permanent corpus, tend to employ fewer staff than endowed foundations of comparable giving size. A large majority of pass-through foundations also show family involvement. These foundations tend to have among the lowest expense ratios of all staffed foundations.
FIGURE 3: Distribution of Charitable Administrative Expenses as a Share of Qualifying Distributions, 2007-2009: Staffed and Unstaffed Independent Foundations

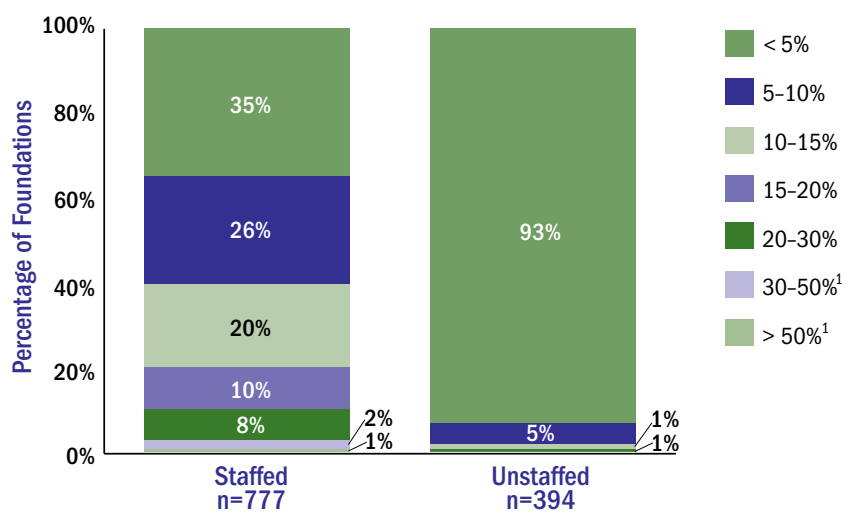

Source: The Foundation Center, 2012; The Foundation Finances Database (2007-2009). Sample includes 1,171 foundations that ranked among the approximately 1,900 largest foundations by giving in 2007,2008 , and 2009 for which data were available for all years; qualifying foundations gave at least $\$ 2$ million each year.

${ }^{1}$ No unstaffed foundations have an average charitable administrative expenses-to-qualifying distribution ratio greater than 30 percent.

\section{What Are Charitable Administrative Expenses and How Are They Measured?}

Charitable administrative expenses are all expenditures related to carrying out a foundation's charitable mission, including expenses for grants administration, direct charitable activities, and general overhead costs. All operating costs that can be counted as part of the "qualifying distributions" that comprise a private foundation's annual payout requirement are included. (Investment-related expenses are not included.)

This study measures the relationship between charitable administrative expenses and qualifying distributions for foundations with or without certain operating characteristics to show how different ways that foundations conduct their work raise or lower expenses. It examines the median ratio (middle value) of expenses to qualifying distributions for each characteristic, using a three-year average (2007-2009). For detailed information on the methodology and the definitions of variables used in this study, see appendices A and B of Benchmarking Foundation Administrative Expenses (published in 2011) at foundationcenter.org/gainknowledge.

FIGURE 4: Charitable Administrative Expenses as a Share of Qualifying Distributions, 2007-2009: Direct Charitable Activities (Staffed Independent Foundations)

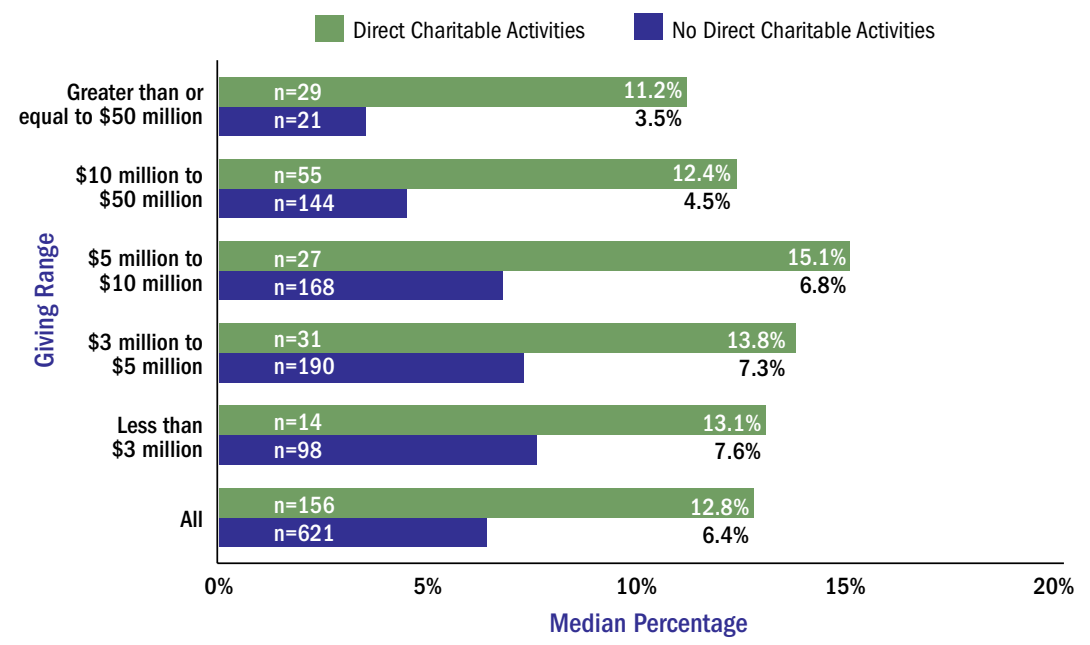

Source: The Foundation Center, 2012: The Foundation Finances Database (2007-2009). Sample includes 1,171 foundations that ranked among the approximately 1,900 largest foundations by giving in 2007,2008 , and 2009 for which data were available for all years; qualifying foundations gave at least $\$ 2$ million each year. Of the 1,171 foundations sampled, on average 777 reported having paid staff. 
FIGURE 5: Charitable Administrative Expenses as a Share of Qualifying Distributions, 2007-2009: Health Conversion Foundations (Staffed Independent Foundations)

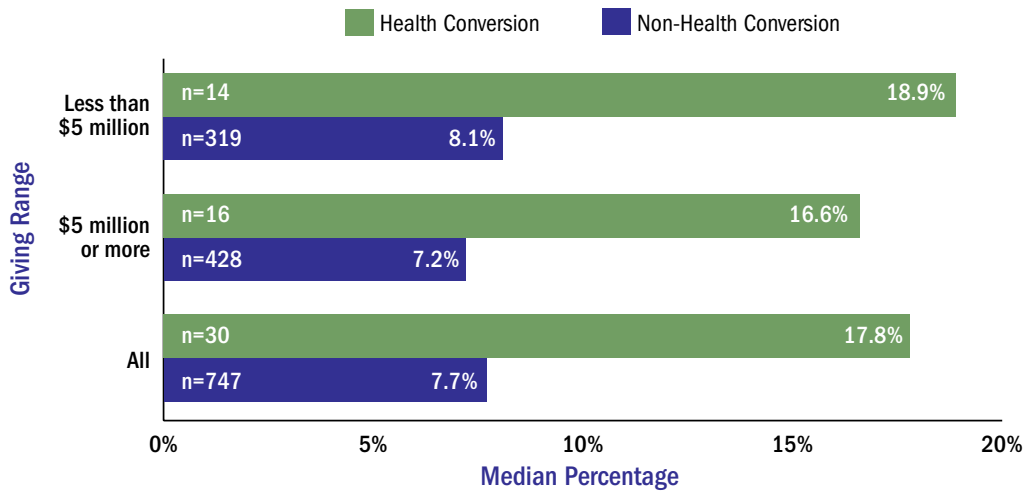

Source: The Foundation Center, 2012: The Foundation Finances Database (2007-2009). Sample includes 1,171 foundations that ranked among the approximately 1,900 largest foundations by giving in 2007, 2008, and 2009 for which data were available for all years; qualifying foundations gave at least \$2 million each year. Of the 1,171 foundations sampled, on average 777 reported having paid staff.

\section{Family Foundations' Lifespan Decisions and Spending Levels}

In general, knowledge is scarce about the lifespan intentions of independent foundations. However, based on responses to a 2008 Foundation Center survey of family foundations, 175 staffed foundations in this study were coded as limited-life (24), perpetual (95), or undecided (56). ${ }^{1}$ For the limited life foundations, the decision to spend down was associated with lower median expense levels than those of all family foundations in the study. The few limited-life foundations had a 4 percent median expense ratio, compared with an 8 percent ratio for foundations that planned to exist in perpetuity or were undecided. The lower ratios of some spend-down foundations correlate with their non-endowed (pass-through) status. But even the largest endowed foundations had very low ratios. Since these foundations have formally opted to spend out their assets, they presumably had greater flexibility than perpetual foundations after the stock market crash to maintain or increase giving. They were also less likely to add costly infrastructure.

${ }^{1}$ The subset of 175 family foundations for which lifespan intentions were known represented 40 percent of the 441 family foundations in this study. Of the 24 limited-life foundations in the sample, 15 had 2007-2009 giving of \$10 million or greater, on average. For information about the survey findings, download Perpetuity or Limited Lifespan: How Do Family Foundations Decide? (foundationcenter.org/gainknowledge)

FIGURE 6: Charitable Administrative Expenses as a Share of Qualifying Distributions, 2007-2009: Family Versus Non-Family (Staffed Independent Foundations)

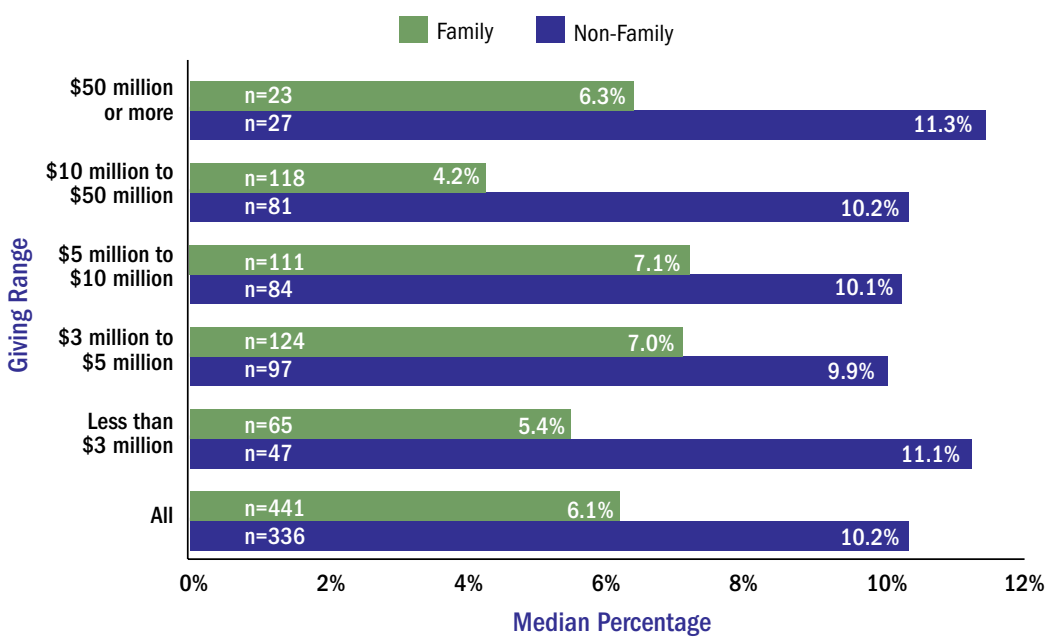

Source: The Foundation Center, 2012: The Foundation Finances Database (2007-2009). Sample includes 1171 foundations that ranked among the approximately 1,900 largest foundations by giving in 2007,2008 , and 2009 for which data were available for all years; qualifying foundations gave at least $\$ 2$ million each year. of the 1,171 foundations sampled, on average 777 reported having paid staff.
Between 2007 and 2009, there was relatively little year-to-year change in the factors that drive expense ratios. Although the three-year average evens out some marked increases in expense levels in 2008 or 2009 , the underlying patterns remain consistent. The characteristics that influence expenses were the same in each individual year and their impact on expense levels was also very similar.

\section{HISTORICAL TRENDS AND STUDY IMPLICATIONS}

\section{Changes in the economy affect asset} and giving levels of foundations and thus the relationship of their expenses to qualifying distributions, but spending patterns tend to even out over time.

Independent foundations are very sensitive to stock market trends since their mandated payout levels are based on their net assets. After growing robustly through $2007,{ }^{8}$ foundation endowments fell victim to the 2008 financial meltdown (Figure 7). Since giving and payout are driven by asset valuation in the preceding year (or over a few years), a majority of foundations reduced their 2009 giving after holding steady or increasing giving in 2008 .

Administrative expenses increased by double digits in this period, perhaps reflecting a delayed adjustment to five years of solid growth in foundation portfolios. ${ }^{9}$ When expense levels increase faster than giving, the expense portion of qualifying distributions increases. Between 2007 and 2009, the yearly median expense ratio for staffed foundations rose slightly. But averaged over three years, the median ratio for this period, was the same as for 2004-2006 (nearly 8 percent).

\section{The factors that drive expense levels of independent foundations were the same in 2007 to 2009 as they were in earlier periods.}

For foundations of comparable size, each of the operating characteristics that had a measurable effect on expense levels in 2001 to 2003 and 2004 to 2006 had a consistent influence on expense patterns in this period, even if the median ratios were sometimes a little higher or lower. Thus, the effect of differences in large foundations' operating characteristics on their spending patterns has now been documented over three consecutive but distinct economic periods 
with strikingly similar results. These findings confirm the importance of a multi-year approach in studying foundation finances. Only a multi-year analysis, repeated over regular intervals and in varying economic environments, evens out annual fluctuations in foundation resources and expenditures thereby providing a more accurate and meaningful interpretation of foundation spending practices.

\section{Foundation oversight and regulation} would benefit from deeper understanding of the diversity of foundations' missions and activities. Foundations' programmatic and strategic choices affect expenses. Assessing data over time reveals the typical expense patterns and the extent of outliers. One-size-fits-all limitations on charitable administrative expense levels or target ratios of expensesto-qualifying distributions would likely have unintended consequences for foundations and the people they serve.

\section{COMPONENTS OF LARGE INDEPENDENT FOUNDATIONS' CHARITABLE ADMINISTRATIVE EXPENSES}

\section{Compensation is by far the biggest component of expenses.}

Compensation accounted for 46 percent of all charitable administrative expense dollars of the largest independent foundations between 2007 and 2009 (Figure 8). In addition to employee salaries and remuneration of officers and board members, "charitable" compensation includes pension plans and other benefits. However, it excludes investment-related salaries and expenses.

\section{After compensation, the other main expense categories by share of dollars are "other expenses" and "other professional fees."}

Between 2007 and 2009, nearly

19 percent of large independent

foundations' expenditures went to each of the categories "other expenses" and "other professional fees." In general, other professional fees refers to consulting services associated with grants administration, accounting, evaluation, etc., while other expenses is a residual category for expenses that do not fit into one of the major line items on Form 990-PF. But because these categories are vaguely defined and are often used as catchalls, it is not clear whether foundations are using the same line items on Form 990-PF to report the same expenses (see below).

The year-to-year distribution of major expense items for large independent foundations is mainly consistent but patterns have shifted over time.

Between 2007 and 2009, compensation's share of expenses stayed about even, while shares of "other expenses" and "other professional fees" increased slightly. When these major items are compared over time, however, a few changes stand out. Notably, between 2004-2006 and 2007-2009, the share of expenses for "other professional fees" increased from 14 percent to 19 percent, while the share for "compensation" decreased from 50 percent to 46 percent. It appears that some foundations, especially the largest ones, are increasingly using consultants to manage their programs. ${ }^{10}$
FIGURE 7: Change in Aggregate Finances for the Largest Independent Foundations, 2007, 2008, and 2009

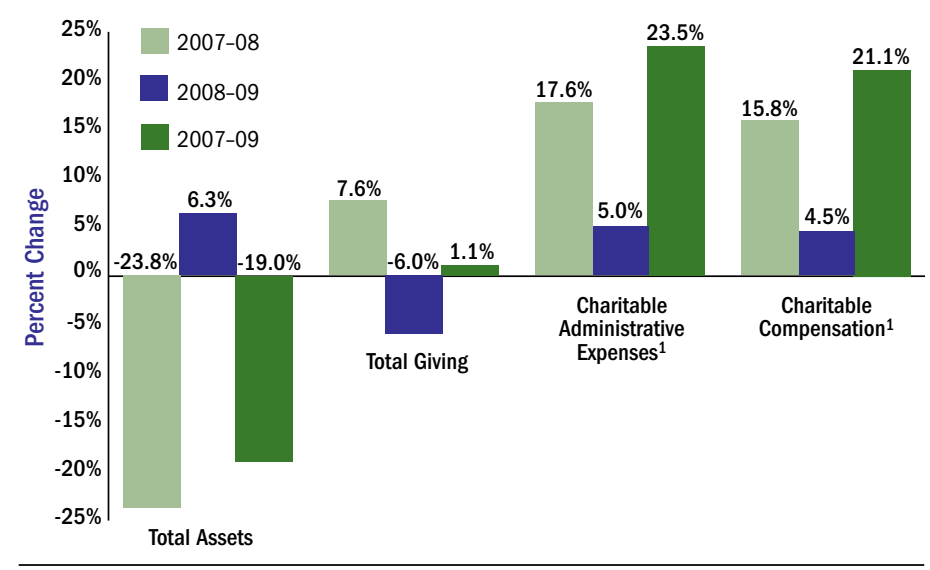

Source: The Foundation Center, 2012: The Foundation Finances Database (2007-2009). Sample includes 1,171 foundations that ranked among the approximately 1,900 largest foundations by giving in 2007 , 2008, and 2009 for which data were available for all years; qualifying foundations gave at least \$2 million each year. The data are not adjusted for inflation.

${ }^{1}$ Charitable administrative expenses and compensation are costs related to the foundation's charitable mission only; they exclude investment-related expenses.
FIGURE 8: Components of Charitable Administrative Expenses for the Largest Independent Foundations, 2007-2009

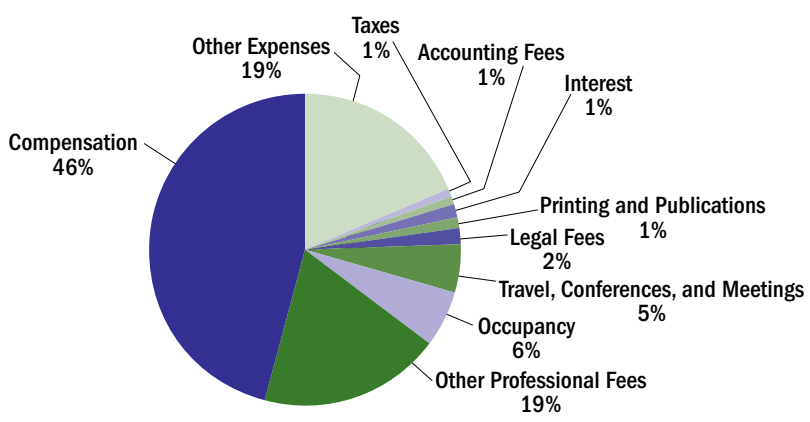

Foundations with Charitable Administrative Expenses

Source: The Foundation Center, 2012; The Foundation Finances Database (2007-2009). Includes 1,029 of the 1,171 foundations sampled that reported charitable administrative expenses. These are costs related to a foundation's charitable mission and exclude investment-related expenses. The data are based on a three-year average for 2007 through 2009. One hundred and forty-two large foundations did not have any charitable administrative expenses. 


\section{Changes in Form 990-PF are needed to improve reporting of foundation administrative expenses and promote greater transparency.}

IRS Form 990-PF-this study's main data source-has not kept up with the changing activities and costs incurred by private foundations in areas such as communications, technology, and evaluation. Nor does it adequately capture foundations' growing involvement in direct charitable activities. ${ }^{11}$ Among the expense categories in the form, "other professional fees" and "other expenses" are especially in need of revision. As noted above, these line items have become catchalls that obscure a significant and increasing amount of operating expenditures.

\section{Foundation Finances and the Economic Crisis: A Different Perspective}

Figure 7 maps aggregate changes in levels of giving, assets, and program-related expenses between 2007 and 2009 for the 1,171 large independent foundations in this study but does not capture the extreme differences in how individual foundations fared. Figure A provides this view for the 1,171 foundations in the study by showing the distribution of all foundations by range of increase or decrease. For example, even though overall giving by these foundations stayed about even in this period, nearly three out of five sampled foundations reduced their giving. And even though the overall charitable administrative expenses of the 1,028 foundations that reported expenses increased by almost 24 percent, nearly one in three of those foundations in fact reduced their spending. ${ }^{1}$ Finally, among the 759 foundations that reported charitable (program-related) compensation, nearly one in three reduced their spending for this purpose. ${ }^{2}$
${ }^{1}$ These findings on changes in the expense levels of the largest independent foundations align broadly with the results of a 2009 Foundation Center survey of foundation practices, although this study's sample is far larger than the survey sample. Of the 429 independent foundation survey respondents, 62 percent had reduced their operating expenses since the beginning of the economic crisis. Among the ways that they had reduced expenses, the most common were to reduce staff travel and/or limit attendance at conferences, freeze or reduce staff salaries, and reduce staff training opportunities. The complete results of the survey are included in Foundations' Year-end Outlook for Giving and the Sector (published in November 2009), available at foundationcenter.org/focus/economy.

${ }^{2}$ Another 412 large independent foundations in the 2007-2009 study paid out no compensation in any year.

\section{FIGURE A: Changes in Finances of the Largest Independent Foundations by Range of Change, 2007-2009}

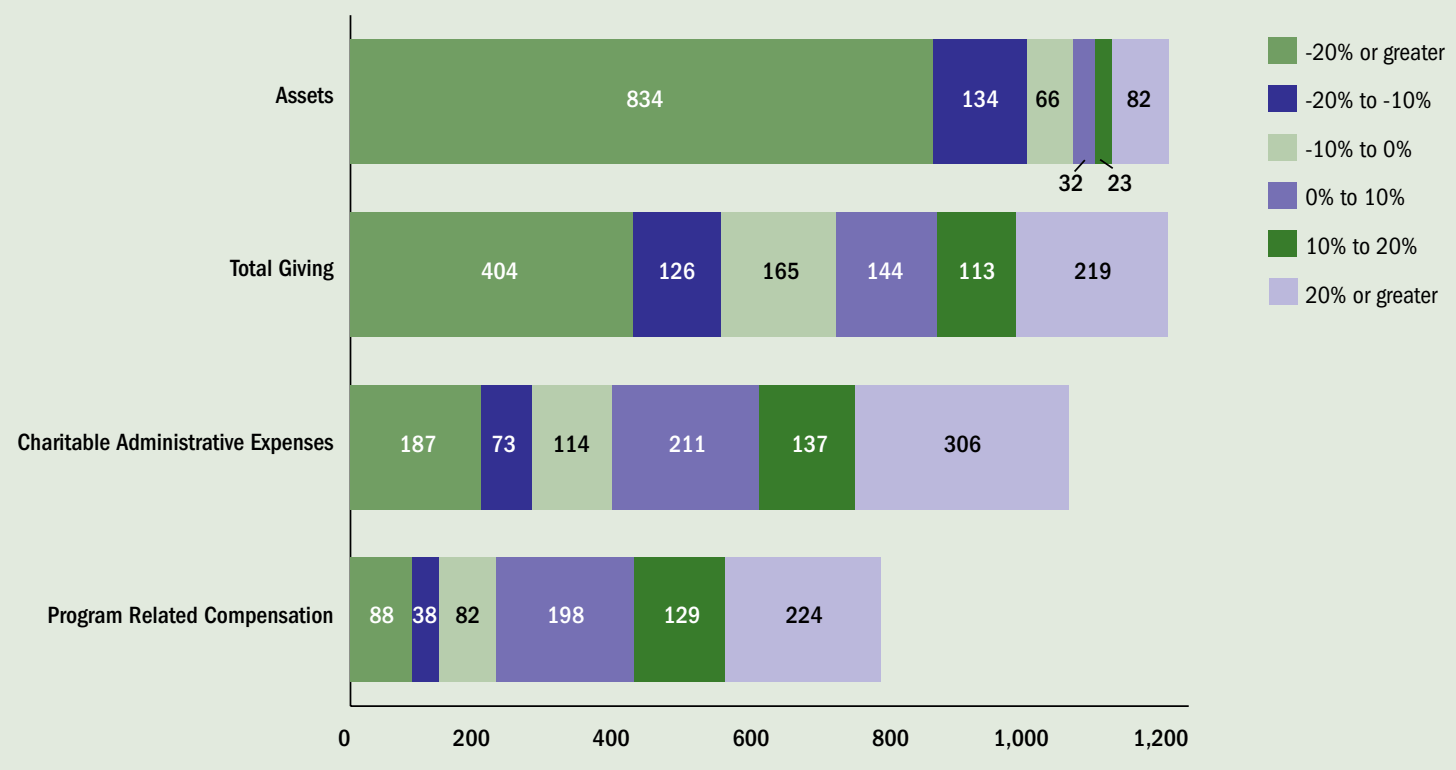

Source: The Foundation Center, 2012: The Foundation Finances Database (2007-2009). Sample includes 1,171 foundations that ranked among the approximately 1,900 largest foundations by giving in 2007, 2008 , and 2009 for which data were available for all years; qualifying foundations gave at least $\$ 2$ million each year. Giving level is based on a three-year average for 2007 through 2009. 


\section{ENDNOTES}

1 Loren Renz, Benchmarking Foundation Administrative Expenses: How Operating Characteristics Affect Spending (New York, N.Y.: The Foundation Center, 2011). This study examined 2004-2006 spending patterns for 1,026 foundations that consistently ranked among the approximately 1,500 largest independent and family foundations by giving amount and for which Form 990-PF was publicly available for all years.

2 Elizabeth T. Boris, Loren Renz, et al., What Drives Foundation Expenses and Compensation? Results of a Three-Year Study (Washington, D.C. The Urban Institute, the Foundation Center, and Philanthropic Research, Inc., 2006). This study examined 2001-2003 spending and compensation patterns for the largest 10,000 independent, corporate, and community foundations, ranked by amount of grants paid in 2001

3 Between 2004 and 2006, 35 percent of the large staffed independent foundations studied had expenseto-qualifying distribution ratios of less than 5 percent, on average, while 88 percent of foundations with no paid staff were in this range. At the high end, 2.2 percent of staffed foundations had expense ratios over 30 percent (compared with 2.7 percent for 2007-2009)
${ }^{4}$ Between 2007 and 2009, three of the four foundations with expense-to-qualifying distribution ratios consistently above 50 percent and eight of the 14 foundations with ratios consistently above 30 percent engaged in direct charitable activities.

5 The proportion of large staffed independent foundations that engaged in direct charitable activities on a regular basis increased from 18 percent in the 2004-2006 study to 20 percent in the 2007-2009 study. By year, the number of foundations that made DCAs increased from 138 (2007) to 155 (2008) to 160 (2009).

${ }^{6}$ Between 2007 and 2009, health conversion foundations represented four of the 14 large staffed independent foundations with expense-to-qualifying distribution ratios above 30 percent each year.

7 Nearly two out of five health conversion foundations studied engaged in direct charitable activities, compared with about one out of five non-conversion foundations.

8 Between 2006 and 2007, asset values of a matched set of 1,151 independent foundations included in this study increased 15 percent. Between 2004 and 2006 , total assets of the 1,026 large independent foundations in the 2004-2006 study of expenses increased 15 percent.
${ }^{9}$ While the direction of assets and giving tends to track the economy, changes in administrative expense patterns generally follow a longer time horizon. Plans to expand institutional infrastructure - especially staff size and program commitments - cannot be easily reversed as assets fluctuate from year to year. This may help to explain why expenses of studied foundations increased by 24 percent between 2007 and 2009, while their asset values fell by 19 percent and their giving levels barely increased. As Figure 7 shows, most of the increase in expenses occurred between 2007 and 2008 , whereas the crash in the stock market came in late 2008.

${ }^{10}$ From 2007-2009, foundations with at least $\$ 500$ million in assets allocated 22 percent of their expenses for other professional fees, on average, up from 16 percent from 2004-2006. Conversely, they allocated 45 percent of 2007-2009 expenses for compensation, down from 49 percent in 2004-2006. "Other professional fees" was the fastest growing expense category of the largest endowed foundations.

${ }^{11}$ For a summary of recommended changes to Form 990-PF, see page 6 of Benchmarking Foundation Administrative Expenses (published in 2011) at foundationcenter.org/gainknowledge.
Source for all data: The Foundation Center

For more information, contact Reina Mukai at the Foundation Center, at (212) 807-2485, or via e-mail at rkm@foundationcenter.org. 